\title{
LOS INTERPRETANTES MEDIÁTICOS DE ELISABETH KÄSEMANN. LA LEY NORMALIZADORA DE LAS REPRESENTACIONES ${ }^{1}$
}

\author{
Media interpretants of elisabeth käsemann. \\ The normalizing law over representations
Os interpretantes mídia de elisabeth käsemann. A lei normalizante de as representações

\author{
Paulo Damián Aniceto \\ CIFFyH de la UNC-CONICET \\ paulodamiananiceto@gmail.com
}

\section{Resumen}

Este artículo se aboca a la descripción del escenario en el que tiene lugar el debate sobre la función de la conciencia individual, la ley y el tiempo en la semiótica peirceana. Asumiendo una perspectiva peirceana no-constructivista, reparamos en el caso de las interpretancias mediáticas de Elisabeth Käsemann como un ejemplo que acude a clarificar la relación entre los eventos de signos y el transcurso del tiempo en el proceso de significación y a asignar un lugar al recuerdo y las expectativas. La verdad completa en la comunicación habita en cada una de sus postergaciones y la verdad del recuerdo está dada por la verdad acordada entre las memorias que los significarán hasta el infinito. La positividad del trayecto de la cadena de signos resuelve la carencia de verdad de las representaciones de la experiencia pero no la precariedad producida por las nuevas ausencias y las correspondientes expectativas.

Palabras clave: Pragmaticismo peirceano. Interpretante mediático. Elisabeth Käsemann.

\begin{abstract}
This article tackles the description of the scenario in which the debate on the role of individual conscience, law and weather takes place in Peirce's semiotics. Assuming a nonconstructivist perspective peirceanian, we repair in media interpretations of Elisabeth Käsemann as an example that comes to clarify the relationship between events of signs and over time in the process of signification and allocate a place to remember and expectations. The whole truth dwells in each of its delays and the truth of memory is given by the truth agreed by the memories that mean to infinity. The positivity of the sign chain solves the precarious truth of representations but does not solve the precariousness produced by the new absences and the corresponding expectations.
\end{abstract}

\footnotetext{
${ }^{1}$ (Este artículo de ensayo fue elaborado en el marco del desarrollo del Curso "Semiótica Peirceana", dictado por el Dr. Fernando Andacht, en el Doctorado en Semiótica del Centro de Estudios Avanzados de la UNC)
} 
Keywords: Peirce's pragmaticism. Media interpretant. Elisabeth Käsemann.

\section{Resumo}

Este artigo enfrenta a descrição do cenário em que o debate sobre o papel da consciência individual, a lei eo tempo em a semiótica de Peirce tem lugar. Assumindo uma perspectiva não-construtivista de Peirce, nós reparar no caso dos interpretantes mídia de Elisabeth Käsemann como um exemplo que vem clarificar a relação entre os eventos de sinais e mais de tempo no processo de significação e atribuir um lugar para lembrar e expectativas. A verdade completa de a comunicação habita em cada um de seus adiamentos e verdade da memória é dada pela verdade acordado entre as memórias que significam para o infinito. Positividade de a cadeia de sinais resolve a falta de verdade de representações da experiência, mas não a precariedade produziu por umas novas expectativas e ausências correspondentes.

Palabras clave: Pragmaticismo de Peirce. Interpretante mídia. Elisabeth Käsemann.

\section{INTRODUCCIÓN}

La identidad de un símbolo en particular es, por lo tanto, esencialmente futurística, en el mismo sentido en el que es verdad que "mañana nunca llega"

(Ransdell, 1977, p. 46)

En este artículo me aboco a la descripción del estado del debate sobre el lugar asignable al discurso mediático desde una óptica semiótica peirciana concentrada en la función de la conciencia individual, la ley y el tiempo. Incorporamos para el análisis teórico el material periodístico comprendido como un conjunto de interpretantes mediáticos de Elisabeth Käsemann. Las notas que componen la serie asisten a la reflexión, son citadas al servicio de clarificar la relación entre el enunciado mediático y el transcurso del tiempo en el proceso de significación y al de asignar un lugar al recuerdo en la comunicación. La verdad completa en la comunicación, en términos peircianos, habita en cada una de sus postergaciones y la verdad del recuerdo es la que ha sido acordada entre las memorias que significará el pasado sobre el discurso en devenir. El carácter positivo de los procesos de sentido resuelve, hasta cierto punto, una carencia de verdad pero no la precariedad producida por las nuevas ausencias y las consiguientes expectativas.

A mediados de 1994, Osvaldo Bayer difundió en Berlín el documental Elisabeth, que sería estrenado en Argentina a comienzos de 2010. El 30 de julio del mismo año, una nota del periódico nacional Página 12 relataba el testimonio de Bayer durante los juicios realizados por

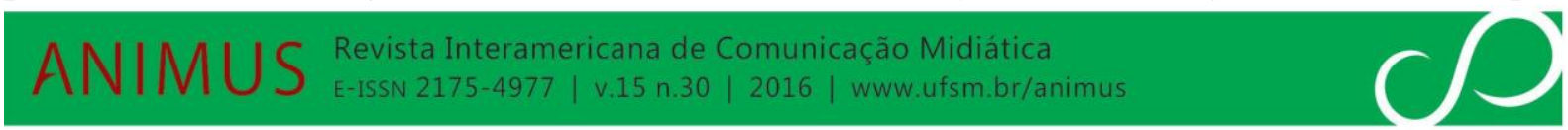


los crímenes del Vesubio, ex centro de detención clandestina. Tres años después, el 23 de septiembre, una crónica de Tiempo Argentino describió la visita del abogado Guido Croxatto a espacios de Berlín donde Elisabeth Käsemann había circulado. A comienzos de 2014, la película Das Mädchen - Wasgeschahmit Elisabeth K.? (La niña - ¿qué pasó con Elisabeth K.?), dirigida por Eric Friedler, fue proyectada por primera vez. Semanas después, el 7 de junio, Bayer publicó en Página 12 una nueva columna de opinión: Colaboracionistas. El escrito considera dos de los testimonios difundidos por el documental de Friedler y el trayecto de Elisabeth Käsemann en Argentina hasta su muerte. Finalmente, el 24 de junio, Sergio Bufano publicó, en el mismo periódico en que días atrás lo hacía Bayer, la nota Kasemann, pacifista o revolucionaria.

\section{DESARROLLO}

\subsection{El (los) recuerdo(s) de Elisabeth Käsemann}

La tarea de asignar categorías analíticas a esta serie organizada de publicaciones requiere precisar una definición elemental de la semiótica lógica peirciana: los componentes de un signo que implica cualidad, existencia y relación. La experiencia albergada en la mente, pasible de asociarse a un objeto del mundo, constituye la denominada Primeridad en el proceso de crecimiento de los signos. La Segundidad, denomina ya una relación de contigüidad o conexión existencial entre la experiencia y el mundo. El proceso de sentido orientado en esta dirección positiva genera en la mentalidad de alguien más una nueva relación signo-objeto. En este punto se produce una relación simbólica por la que una Terceridad evalúa y sanciona la relación Segunda entre un signo y el mundo observado. Esta otra mentalidad, afirma Peirce, representa el criterio científico comunitariamente consolidado que, al evaluar la relación sígnica, se convierte a su vez en un signo a ser evaluable por otra Terceridad, también generada en el perímetro de una comunidad de pensamiento. Empeñamos nuestro análisis a describir el estatus simbólico del recuerdo, su calidad de Tercero, siempre que pone en relación el pasado, por un lado, y otros recuerdos que le anteceden en el tiempo.

Elisabeth Käsemann nació en Gelsenkirchen, Alemania, el 11 de mayo de 1947. Estudió Ciencias Políticas, en Otto-Suhr-Institutfür Politikwissenschaft de la Freie Universitat, Berlín y, en 1968, se radicó en Buenos Aires. Los motivos de su decisión, sus objetivos en Argentina, su participación en organizaciones sociales y su trágica muerte, nueve 
años después, constituyen elementos de una verdad precaria, significada y re significada en sucesivos interpretantes del espacio mediático argentino. Este trabajo aborda, adoptando una perspectiva semiótica peirciana, el flujo de sentido en el que la cualidad absoluta Elisabeth Käsemann persiste generando otros eventos de signos (Debrock, 1991) y como expectativa, siempre frustrada al final, de conocimiento consumado. "Un signo es cualquier cosa que determina algo más (su interpretante) a referir a un objeto al cual él mismo refiere (su objeto) de alguna manera, el interpretante se convierte a la vez en signo, y así hasta el infinito" (CP. 2.303 en Ransdell, 1997). Cada interpretante de Elisabeth Käsemann sucede en un segmento de tiempo que sustituye a uno anterior, donde otro evento interpretante había tenido lugar. Este proceso de significación desarrolla el conocimiento de la verdad del objeto al tiempo que la normaliza. Necesariamente debemos considerar que la verdad de lo representado está ausente toda vez que permanece pendiente de significación. Sobre este espacio es que se desliza la primera relación contingente, indicial, entre el sentido y el tiempo: verdad-horizonte de expectativa.

Aproximamos, en un primer momento, los principios elementales del pragmaticismo peirceano que ofrecen, desde la perspectiva denominada no-constructivista, respuestas a la cuestión polémica de la ley normalizadora de las "representaciones válidas" y la confrontan a las posibilidades de la creación y la novedad.

\subsection{La semiótica peirceana no-constructivista y la psicología del desenvolvimiento}

Ransdell (1997), en On Peirce's conception of theiconic Sign, asegura que Peirce entendía la semiótica como una disciplina que debía desarrollarse arquitectónicamente, desde pocos y relativamente simples pero abstractos principios que establecerían una red de concepciones sistemáticas. El autor presenta los aportes teóricos peirceanos y vuelve su atención sobre el elemento abordado diferencialmente por estudios semióticos actuales: la conciencia.

Perspectiva constructivista. Da Silveira (2004, p.76) considera que el conocimiento del objeto representado se realiza "como expresión evolucionada de una comunidad que camina en vista de lo que se le ofrece como objeto de deseo y realización”. El autor se integra a la corriente constructivista de la semiótica peirceana vinculada a la psicología del desenvolvimiento y la semiótica de la cultura rusa. Esta es una perspectiva enfocada en la productividad de subjetividades y en una visión de un sujeto que aplica las reglas de su 
comunidad de pensamiento sin delegar su participación activa, consciente e instituyente. Es decir, la masa abundante de cualidades de los objetos representados en los medios, una totalidad en potencia, y sus representaciones emergentes no obedecen a un proceso de sentido socialmente trazado (Ransdell en Andacht, 2003) sino a modulaciones de una inteligencia individual. En la misma línea se inscriben los estudios de Vincent Colapietro (1995, p.482), cuyo planteo considera, en definitiva, que es posible desarrollar un abordaje semiótico de la inconsciencia y comparar esta aproximación con las realizadas por Sigmun Freud, Carl Jung, Jacques Lacan, Julia Kristeva y otros.

Fernando Andacht (2013, p.24) distinguió los enfoques peirceanos constructivista y no-constructivista en estos términos:

\footnotetext{
"la voz del influyente psicólogo/filosofo del lenguaje ruso Vigotski, nos propone aquí otra forma de pensar nuestros signos, una que es aliada a la consciencia, a la subjetividad, un camino que la lógica antipsicologista (pero no antipsicológica) de Peirce evita para construir su teoría de la semiosis, de la acción de los signos autónoma y teleológica".
}

En el amplio campo de perspectivas peircianas de la comunicación, también reconocemos aquella que entiende la conciencia como un esquema de asimilación y mediación, incorporado en la pertenencia a una comunidad de pensamiento con límites poco claros. Guy Debrok (1991, p.56) asegura que "el contexto completo indica que la mente misma ha sido producida por representaciones naturales". La concepción de un redactor de un periódico innovador, creador de símbolos inéditos no tiene lugar, aquí, ante la idea de una inteligencia colectiva normalizadora del proceso significante de la comunicación. En esta dirección se orienta también la propuesta del norteamericano Michael Shapiro (2002). En Aspects of a Neo-Peircean Linguistics, recupera la noción de deriva introducida por Edward Sapir para sostener que "la deriva de un lenguaje es constituida por selecciones inconscientes" (Shapiro, 2002, p.112).

\subsection{Conciencia y causalidad}

Shapiro (2002) considera que la afirmación sobre la innovación de lo inédito debe ser vista como un error de categoría. Una lectura que hace prevalecer la voluntad individual en la producción de símbolos asume la existencia de causas. Es decir, la comunicación creativa produciría la introducción de elementos nuevos. En oposición, el peircianismo no- 
constructivista sostiene que la cobertura de aspectos de un hecho de la actualidad no se instaura como la "causa" de futuras coberturas sino como un evento de signo (Debrock, 1991) que expresa la esperanza de apresar el conocimiento de la actualidad total. Shapiro (2002, p.122), sobre esta esperanza siempre frustrada de captar el fundamento primero de las cosas, asegura que "Peirce entendió una causa final como siendo una posibilidad, que tiene una tendencia a convertirse en actual, de una manera u otra". Aquí vemos, por lo tanto, al argumento de "lo causal" constituirse en un alegato en defensa de la posibilidad de arribar a la verdad primera de la actualidad, independiente y autónoma de toda representación mediática.

Aquí resulta clarificador acudir al caso de las interpretancias de Käsemann. Nos detenemos en la crónica de Guido Croxatto sobre los efectos del contacto sensible con el espacio físico por el que habría circulado Elisabeth Käsemann mientras vivía en Alemania. "Fue muy fuerte pisar, estar, respirar, en el mismo edificio en la Freie Universitat, en Berlín, donde estudió Ciencia Política una joven y valiente y hermosa mujer, Elisabeth Käsemann". La descripción de la fuerza de las sensaciones se constituye en su interpretante y las sensaciones mismas, en el interpretante de la conexión sensitiva dada en 'pisar', 'respirar' y 'estar'. Y en definitiva, el hecho de haber pisado y estado allí, implican acciones mediadas por la manera singular en que el cronista comprendía la historia de la joven alemana y lo que los muros, pisos y aromas representaban de esa historia. Por lo demás, a la crónica de Croxatto le seguirían nuevas interpretantes mediáticos futuras.

Con todo, la potencialidad de lo por conocer sobre Käsemann no es agotada en las cualidades exhibidas por las imágenes de un diario matinal, sino en el devenir de otra Terceridad que indica lo cognoscible sobre ella en publicaciones mediáticas y relatos orales urbanos. El futuro de las actuales representaciones de "la actualidad" desarrollará y corregirá el conocimiento de los acontecimientos que, sin embargo, quedará siempre incompleto. La significación completa se constituye, en el transcurrir de la cadena de signos, en una instancia sucesivamente postergada. "Este proceso es necesariamente siempre histórico y no dado a priori” (Shapiro, 2002, p.123).

\subsection{La temporalidad de las representaciones}

Como dijimos, a diferencia del peircianismo no-constructivista, que postula la percepción "mediatizada a través de un conjunto complejo de convenciones" (Ransdell en Andacht, 2003, p.228), el constructivista sostiene que el acto de creación individual superaría 
el umbral de las habilidades perceptuales comunitarias y conservaría el privilegio de incluir lo nuevo. Esto motiva una observación sobre el tiempo en las representaciones mediadas.

El individuo capaz de abstraerse del flujo de pensamientos-signos que desarrollan el conocimiento de los hechos de la actualidad, también podría clasificar unos pensamientos como antiguos y otros, los suyos, como novedosos. Son didácticas, en este punto, las instrucciones de Peirce sobre el plano diacrónico de la sucesión de pensamientos-signos. El pensamiento, según el lógico norteamericano, se produce en un instante de tiempo imposible de percibir inmediatamente. En ese instante no hay duración. Por lo tanto, el pensamiento, al próximo instante, habrá sido sustituido por otro que lo retomará y, así, ad infinitum.

Pensamos en un instante del tiempo pero nos resulta imposible percibir inmediatamente su transcurso. En un instante no hay duración y, por lo tanto, tampoco una percepción inmediata de la duración (Peirce, C. \& Carmen Ruiz, 2001; CP 5.213-63). A la luz de esto, cabe preguntarse ¿cómo es posible que el cronista de un medio que se encuentra en el pensamiento, y no a la inversa, perciba lo viejo y la necesidad de lo nuevo e impulse un acto concreto de transformación si no es consciente de la duración de sí mismo en ese instante de tiempo? ¿En qué medida la oposición creatividad/convenciones puede ser sostenida en el marco del pragmaticismo peirceano? ¿En qué lugar se ubica la Terceridad normalizadora que aplica la ley de las representaciones aceptables sobre las representaciones posibles?

\subsection{La ley como ley localizada}

El interpretante mediático es una mediación entre el sentido de una representación emergente en los medios y el sentido con el que un nuevo interpretante la sustituirá en el devenir ${ }^{2}$.

El hecho de que el sí mismo, el self (Andacht, 2008), constituya para el no-constructivismo una subjetividad cuyas operaciones debamos suscribir a una comunidad de pensamientos, plantea un interrogante: ¿debemos hablar de la represión de la ley sobre del potencial icónico o de una mentalidad individual no-consciente con habilidades perceptuales adquiridas en su pertenencia a una comunidad normalizadora y en evolución? No es una ley opresora la que

\footnotetext{
${ }^{2}$ Lo cual explica las palabras del mismo Peirce (\& Barrena, 1997; CP 6.455), cuando afirma: “(...) such is everything which is essentially a Sign-not the mere body of the Sign, which is not essentially such, but, so to speak, the Sign's Soul, which has its Being in its power of serving as intermediary (...)". (Tal es todo lo que esencialmente es un signo -no meramente el cuerpo del signo, que no es esencialmente tal, sino, en pocas palabras, el alma del signo, que tiene su 'ser' en su poder de servir de mediación)
}

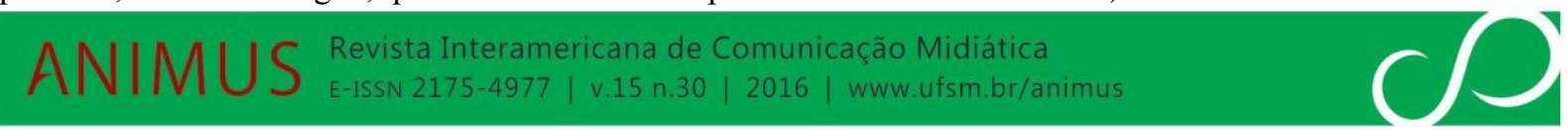


delimita ese potencial, sino la sucesiva insuficiencia de los signos para significar la experiencia la que se convierte en la fuerza que alienta, desde el devenir, la representación de algunos aspectos de los universos de experiencia y la exclusión de otros.

Una de las columnas de opinión publicadas en Página 12, en contexto de circulación de la nota de Olvaldo Bayer -Colaboracionistas-, contribuye a comprender la relación normalización-evolución, que cobra vida en los procesos de sentido. Sergio Bufano, que firma la columna, sanciona la caracterización de Elisabeth Käsemann realizada por Osvaldo Bayer como no ajustada a la realidad. Bufano pronuncia la voluntad de su descripción: "para que nos aproximemos a su personalidad y su conducta". En su relato argumentativo sobre una joven revolucionaria, configura un interprentante corrector de interpretantes anteriores, tomando a cargo una inferencia que permanece implícita: Como lo demuestran las nuevas cualidades atribuidas aquí a Käsemann, el 'ser revolucionario' es excluyente de la posibilidad del 'ser solidario'. Uno de los fragmentos grafica la hipótesis implicada en el nuevo interpretante: "afirmar que Elisabeth era una pacifista que ayudaba en los barrios es un error. Porque no lo era. Porque, como toda esa generación, aspiraba a protagonizar una revolución socialista que acabara con la injusticia social" (el destacado es mío). El interpretante emergente en la nota de Osvaldo Bayer del 7 de junio de 2014 aparece asignando relaciones entre las declaraciones de un documental que Bayer aseguró haber visto y sus nociones sobre el terrorismo de Estado y la joven alemana. Estas relaciones, enfocadas por la óptica peirciana no-constructivista, han sido acuñadas en la adscripción de las representaciones individuales de Bayer a una determinada comunidad de pensamiento, y tal adscripción, suscrita y convalidada a través de un proceso histórico y complejo de marchas y contramarchas. Podríamos atribuir las mismas funciones a las interpretancias mediáticas que constituyen las proyecciones de los documentales sobre Käsemann y los relatos de Bufano posteriores a los de Bayer.

Las consecuencias prácticas de toda mediatización de la experiencia existen en primera instancia en la expectativa comunitaria de sentido y es dicha expectativa la que direcciona la generación de interpretantes de un mismo hecho de actualidad en los medios. Esta definición general del ámbito de la lógica pragmática es traducida por los numerosos trabajos de Fernando Andacht al de los estudios del discurso mediático. En uno de ellos, Andacht (2012) recuerda que, para Peirce, la mediación es análoga al ejercicio de apuntar al blanco, en el cual se observa la influencia del futuro en el presente mediante la acción de la 
mente que anticipa el objetivo y en base a éste imparte direccionalidad a la fuerza física, ciega y compulsiva.

Una vasta cadena de interpretantes significan y re-significan las representaciones mediáticas de Elisabeth Käsemann. El ajuste a la realidad pura y total de una joven asesinada en 1977 -como lo demanda el interpretante asignado en la nota de Bufano-, se debate en la sucesión de sus representaciones, que confirman que el recuerdo de Elisabeth es lo que será en sus recuerdos posteriores. Desde el enfoque que valora la sanción comunitaria de las representaciones individuales, el material que seleccionamos configura una unidad de análisis de lo falible de las representaciones mediáticas. Los juicios de valor de Bufano sobre la semblanza elaborada por Bayer son inferencias de una falibilidad análoga a la de las inferencias del mismo Bayer. Éstas habían sido formuladas por él, a su vez, a partir de apreciaciones evaluativas del documental de Eric Friedler, La niña - ¿qué pasó con Elisabeth K.? Por lo demás, en el horizonte futuro de esta cadena de interpretantes, se encontraba el interpretante consumado desde ahora en estas líneas de análisis teórico.

Ahora bien, ¿la normalización llevada a cabo por lo comunitario puede regular las potenciales representaciones y mediar la percepción individual sin convertirse en un tirano temible de lo real y lo posible? Esta es una cuestión que cobra relieve en el debate entre los exponentes actuales del pensamiento peirciano.

Da Silveira (2004) asume en relación con esto una posición constructivista. Para percibir los hechos de la realidad y representarlos, "se supone que los admiremos y nos dejemos ser por ellos atraídos" (75). Así confirma la posibilidad de un individuo inteligente que primero decide restringir una potencialidad y luego liberarla y otorgar su capacidad de decisión a una realidad autónoma que lo 'atraerá'. Lo naturalmente admirable de los fenómenos de la actualidad (da Silveira, 2004) conduciría hacia las representaciones del sujeto que ha cedido a su llamado. La ficción de un individuo que se permite ser atraído por un objeto de deseo delata la de uno que se preserva la potestad consciente de prohibirlo.

Los interpretantes mediáticos de Käsemann contribuyen a comprenderlo. La publicación de la columna de opinión de Osvaldo Bayer, Colaboracionistas, constituye una instancia posterior al encuentro del columnista con las declaraciones editadas por el documental de Eric Friedler. La irrupción, en el montaje documental, de las palabras del ex ministro del gobierno alemán de 1977 produce efectos perceptivos inmediatos en Bayer, previos aún a la decisión irreversible de empuñar un bolígrafo y redactar una nota publicable. 
Un hecho real se entromete de modo forzoso e impide ser ignorado (Andacht, 2013). Desde un enfoque no-constructivista, debemos asumir la frase "Me toca muy a fondo este caso", pronunciada por Bayer, como un interpretante generado por la percepción que el documental forzó en su mente. Un interpretante mediático no es un acto de voluntad de un periodista capaz de dominar el flujo de sentido, sino la constitución de un nuevo signo en el proceso de mediatización de la realidad. Su significación como nueva representación no le he es dada en su misma generación, sino en la inminente operación de un nuevo signo en devenir.

Parece necesario identificar la distancia entre una instancia lógica -un interpretante mediático- de la acción de interpretación, agenciada en el redactor de un periódico o el notero. El interpretante, en palabras de Debrock (1991, p. 57), “es una representación de algo representándose a sí mismo como la representación de alguna otra cosa”. Si asignamos, en estos términos, a la solicitud de Bayer para la proyección del documental Elisabeth durante una audiencia judicial como interpretante, ésta constituye una representación de otra representación (la proyección) que la categoriza de probatoria. Finalmente, el sentido de posibilidad/imposibilidad de la representación probatoria fue atribuida por un nuevo signo interpretante: la denegación del tribunal para la proyección. La verdad jurídica predominante es la cualidad que los interpretantes de esta secuencia (Documental, Bayer, Tribunal) anuncian poseer. Sin embargo, es insoslayable la existencia de una racionalidad legal (tan sedimentada comunitariamente como la racionalidad mediática) que pone constantemente en relación los medios emergentes para su alcance con los medios aceptables.

\subsubsection{La ley y los intérpretes}

Lo que muchos asumen como regulación impiadosa del potencial que un grifo abierto podría liberar, merece aquí otras observaciones sobre lo regulador y la posibilidad de pensar en un acto de voluntad capaz de abrir tal grifo.

La perspectiva peirceana no-constructivista entiende, en palabras de Ransdell (1997, p.12), que:

Estamos acostumbrados a pensar que, como intérpretes y usuarios de los signos, los tenemos en nuestro poder para dar significados a las cosas por puro acto de voluntad e intención (...) hablamos sobre inventar lenguajes que de alguna manera serán libres de las limitaciones inherentes en las palabras que usamos en el proceso de invención de esas cosas nuevas. 
En la columna de opinión firmada por Bufano, es posible advertir el signo de una voz que se arroga, en el campo de posiciones mediáticas, la exclusividad para asignar un conjunto de cualidades a una cosa. El acto consciente de la nota periodística traduce el diálogo antagonista con la nota de Bayer por el sentido del recuerdo fiel de Käsemann. Sin embargo, es posible reconocer un evento de signo que la voluntad de fidelidad del mismo Bufano inadvierte: un nuevo interpretante de los límites entre el ser revolucionario, ser pacífico y ser solidario.

Por esto, reconocer la perspectiva no-constructivista en su anti-antropocentrismo nos re posiciona frente a la imagen bastante asumida de una ley conservadora que restringe la facultad creativa de los hombres.

Las cualidades asignadas por la nota periodística de Sergio Bufano al ser revolucionario como cualidades exclusivas de los sujetos que ejercen violencia en pos de la justicia social no provienen de un criterio de clasificación elaborado por Bufano. Son orientadas, más bien, por un conjunto limitado de cualidades consideradas por una comunidad de pensamiento como asignables a las personas que, al optar por alcanzar el cambio por medios violentos, se diferencian de aquellas que lo aspiran por medios no-violentos. Bayer, reconocido en Argentina por sus antecedentes como escritor, novelista y guionista de afiliación anarquista tampoco inaugura, desde una imaginable voluntad creadora, nuevos paradigmas conceptuales para entender la militancia solidaria, las actitudes violentas y sus cualidades diferenciales. En él, las formas aceptables de comprender lo revolucionario coinciden, en parte, con lo considerado por la matriz anterior. La diferencia está centrada en sus representaciones del uso de la violencia. En definitiva, la redacción de Bufano implica un interpretante que atribuye violencia a las víctimas de la dictadura y la pone en relación con su representación en la nota de Bayer. Es posible sustraer el significado asignado por Bufano a esa relación: el reconocimiento de la violencia de una víctima no excluye automáticamente la necesidad de justicia.

Queda a la vista la medida en que el significado de la nota de Osvaldo Bayer no deriva de un razonamiento anterior basado en una premisa fundamental. Su significación le fue investida por un conjunto de interpretantes posteriores, entre las que asignamos la columna de Bufano.

\subsubsection{La forma de la restricción}


Recuperamos, en este punto, la condición de criticismo moderado que Peirce (\& Restrepo, 2003; CP 2.227-229) atribuye a la mente de los integrantes de una comunidad científica. El musement, mediante el cual el individuo llega a una hipótesis que considera plausible, se constituye en un instinto normativizado. La belleza estética de la descripción de la canoa del musement lejos está de identificar la conciencia a la voluntad antojadiza. Retomada desde aquí, la imagen de la canoa del musement representa un hombre que navega y conduce sus movimientos mediante reflejos aprendidos para la navegación aceptable en el seno de una comunidad.

En lo que reconocemos una contradicción teórica, durante una entrevista realizada por Andacht (2003), Ransdell relató la manera que él había establecido de educar en el consumo de la imagen televisiva. No se debe impedir su recepción, según indicaba, sino "volverla disponible y entrenar a mis hijas en cómo lidiar con ella de modo inteligente" (234). Es necesario debatirle a este planteo sus implicancias simbólicas. Aquí entendemos esa mentalidad que entrena las habilidades de consumo como históricamente constituida en el seno de una familia estadounidense con preferencias didácticamente aprendidas, subsumida a un régimen singular de libertad y regulación. Redundaríamos si intentáramos identificar las mentalidades que esa mentalidad ejercita. La ausencia de un televisor no resulta más restrictiva que el acto de entrenarlas en una inteligencia que rija la recepción del potencial simbólico. ¿No estaríamos, en el acto mismo de provisión de libertad para ese potencial icónico de la TV, estableciendo nuevas formas de limitar su poder de emancipación? Es sabido, el instrumental que despeja los nubarrones de la restricción y conduce a la libertad no es otra cosa que la aplicación de estrategias de un dominio que impone los límites de lo aceptable.

\subsection{Estatus simbólico del recuerdo}

¿Cómo operan los signos a los que atribuimos la representación de hechos pasados? ¿Qué funciones despliegan las sucesivas representaciones de la joven Elisabeth Käsemann al recordarla? Ransdell (1997, p.61) retoma, con un enfoque no-constructivista, las relaciones asignables entre los pensamientos-signos y el acto del recuerdo: "en rigor, no percibimos nada a través de nuestros sentidos pero el pasado, el mero hecho que el objeto es en el pasado, no puede, él mismo, ser una objeción para decir que el recuerdo verídico es una percepción directa del objeto recordado". 
La memoria no infiere de la observación del hecho fáctico, sino que desarrolla el conocimiento del pasado a partir de las sucesivas representaciones conmemorativas previas habían transmitido sobre él. Esta conclusión parece ir de suyo pero deriva en observaciones que especifican la función programática del recuerdo en la cadena de signos. Así, la verdad de los hechos del pasado está dada por la verdad acordada entre las memorias que los significarán hasta el infinito.

El recuerdo no es un interpretante de la relación entre unos vestigios del pasado y el hecho sucedido sino entre un signo que representa algunos aspectos del pasado representados, a su vez, por otros signos. Relación entre el primer acto de rememoración de Elisabeth Käsemann y los sucesivos de un proceso social de sentido. Son representadas cualidades generalmente asignables por un saber compartido a jóvenes europeos de la década de los 70’ e imágenes convencionales sobre las dictaduras, disponibles en la memoria colectiva.

Con todo, los testimonios que re-significarán el pasado de Käsemann y al mismo tiempo significarán las representaciones actuales están en el futuro del testimonio.

\section{7 'La verdad' y su precariedad}

Como vimos, la conciencia sobre el objeto, obtenida de la experiencia, es el producto de un proceso histórico desenvuelto en el ejido de una comunidad. Ahora bien, ese proceso es propulsado por lo que Peirce (\& Vericat, 1988; CP 5.264-317) denomina fuerza efectiva real, subyacente a la conciencia misma. La fuerza efectiva real es uno de los principales elementos de la fenomenología peirciana de los signos, porque asocia la cognición con la sucesión y el crecimiento progresivo y paralelo de la matriz que determina las leyes de la inferencia. Como nos señaló Eco (1992), debemos asumir que existe una pasión trascendental que evoca la existencia de una comunidad como garante intersubjetiva de la verdad ${ }^{3}$.

Maurice Halbwachs (2004) ya había reflexionado en estos términos. En La mémoire collective: cadres sociaux de la mémoire, el sociólogo consideraba que el individuo no recuerda solo, sino con la ayuda de los recuerdos de otros. Paul Ricoeur (2000, p.126) lo retoma en las siguientes palabras.

\footnotetext{
${ }^{3}$ Umberto Eco plantea que la verdadera noción de realidad envuelve una noción de comunidad creando un significado intersubjetivo (Eco, 1992). En consonancia, Ransdell (1997, p. 25) nos recuerda que "la teoría de Peirce es una descendencia lógica de Kant”.
} 
(...) uno de los aspectos principales quizá consista en que nuestros recuerdos se encuentran inscritos en relatos colectivos que, a su vez, son reforzados mediante conmemoraciones y celebraciones públicas de los acontecimientos destacados de los que dependió el curso de la historia de los grupos a los que pertenecemos.

El objeto del documental Elisabeth fue significado por un nuevo documental. El proceso de significación se desplegó en sucesivas publicaciones mediáticas, significadas, a su vez, en estas páginas. Como vimos y nos recuerda Ransdell (1997, p.28), "lo que un signo genera es otro signo, cualquier cosa que puede jugar el rol del interpretante en una actualización". El ser de la actualización en la que Ransdell ubica al interpretante parece aludir a un punto del desarrollo del conocimiento que se encuentra, instante a instante, en expectativa. Diremos, por lo tanto que la verdad de la significación mediática de un hecho de la actualidad, por lo tanto, habita en cada una de sus postergaciones.

A esto, Shapiro (2002, p.19) agrega que "todos los interpretantes dinámicos están a la altura de la verdad plena sobre el objeto dinámico del signo" y que "el interpretante final es un ideal que podría ser aproximado pero nunca alcanzado". El transcurrir del tiempo y el trayecto positivo de la cadena de signos resuelve la carencia de verdad de las representaciones de la experiencia pero no resuelve la precariedad producida por las nuevas ausencias y las correspondientes expectativas. "No hay signos a menos que haya expectativas", nos confirma Debrock (1991, p.60). El único a priori que precede determinando el signo está dado por la posibilidad y se encuentra en el devenir del significado.

\section{CONCLUSIONES}

El análisis semiótico orientado por una perspectiva peirceana no-constructivista no ha perdido vigencia como medio de abordaje de las relaciones triádicas del discurso mediático. Es adoptando este enfoque que entendemos las relaciones de implicación lógica establecida entre los signos de una cadena de pensamiento-signos.

Los efectos en mí del material referido a Elisabeth Käsemann que hoy se acumula ante mis ojos; los aids (Andacht, 2008) o ayudas (Halbwachs, 2004) de la memoria aprendida sobre las dictaduras militares en Argentina junto a una foto de Elisabeth que una de las notas me exhibe; mi primer impulso, ininteligente, que orienta una palabra, una duda o una pausa. 
No son éstos elementos de contornos nítidos, sino unidades abstraídas en una relación de interacción simbólica.

Por lo demás, afirmar la posibilidad de la innovación y la creatividad en las representaciones mediáticas, fundante de nuevas normas, equivaldría a reavivar los principios del convencionalismo nominalístico que creía en la ficción de una cita legislativa que las habría instaurado deliberadamente. Los cambios se dan a pesar de la voluntad de un periodista o un grupo de ingenieros de la información. Ellos no abordan la canoa del musement sin contar con las instrucciones de navegación.

\section{REFERENCIAS}

ANDACHT, F. Joseph Ransdell entrevistado por F. Andacht. De signis, n 4, p. 221-234, 2003

ANDACHT, F. Self y creatividad en el pragmatismo de C.S. Peirce: la incidencia del instante presente en la conducta. Utopía y Praxis Latinoamericana, v. 12, n 40, p. 39-65, 2008.

ANDACHT, F. Una puesta en escena de la mediación narrativa: el documental Jogo de cena como espacio experimental. Mediálogos. Revista de Comunicación de la Universidad Católica de Uruguay, n 2, p. 120-134, 2012.

ANDACHT, F. Análisis de un episodio de la miniserie cidade dos homens como una fábula indicial", Situarte. Revista de la Facultad Experimental de Arte de la Universidad de Zulia, Maracaibo, v. 7, n 14, p. 9-19, 2013.

BAYER, O. Colaboracionistas. Página 12, 7 de Junio de 2014. Disponible en http://www.pagina12.com.ar/diario/contratapa/13-248027-2014-06-07.html. Consultado el 20 de agosto de Agosto.

BUFANO, S. Käsemann, pacifista o revolucionaria. Página 12, 24 de Junio de 2014. Disponible en http://www.pagina12.com.ar/diario/elpais/1-249265-2014-06-24.html. Consultado el 20 de Agosto de 2014.

COLAPIETRO, V. Notes for a Sketch of a Peircean Theory of the Unconscious. Transactions of the Charles S. Peirce Society, v. 31, n 3, p. 482-506, 1995.

CROXATTO, G. Elisabeth Käsemann. Tiempo Argentino, 23 de Septiembre de 2013. Disponible en p. 14 de https://issuu.com/tiempoargentino/docs/nacional_d72d49a3f57eac

DA SILVEIRA, B. Observe-se o fenómeno: forma e realdade na semiótica de Peirce.

Cognitio. Revista de Filosofia, v. 5, n 2, p. 72-77, 2004.

DEBROCK, G. La información y el estatuto metafísico de los signos. Comunicación y

Sociedad. v. 4, n 1-2, p. 53-64, 1991. Disponible en

www.unav.es/users/TraducciónDebrok.html). 
ECO, U. Los límites de la interpretación. Barcelona: Lumen, 1992.

GINZBERG, V. Pidieron plata por el cuerpo. Página 12, 30 de Junio de 2010. Disponible en http://www.pagina12.com.ar/diario/elpais/1-148565-2010-06-30.html.

HALBWACHS, M. Los marcos sociales de la memoria. Barcelona: Anthropos, 2004.

KOSELLECK, R. Futuro pasado. Para una semántica de los tiempos históricos. Barcelona: Paidós, 1993.

PEIRCE, C. \& RUIZ, C. Cuestiones acerca de ciertas facultades atribuidas al hombre. Publicado en CP 5.213-63, 2001 [1868]. Disponible en http://www.unav.es/gep/QuestionsConcerning.html.

PEIRCE, C. \& BARRENA, S. Un argumento olvidado a favor de la realidad de Dios. Publicado en CP 6.452-485, 1997 [1908] Disponible en http://www.unav.es/gep/Argument.html

PEIRCE, C. \& VERICAT, J. Algunas consecuencias de cuatro incapacidades. Publicado en CP 5.264-317, 1988 [1868]. Disponible en http://www.unav.es/gep/AlgunasConsecuencias.html.

RANSDELL, J. Some Leading ideas of Peirce's semiotic. Semiótica, v. 19, n 3-4, p. 157-178, 1977. Disponible en Arisbe The Peirce Gateway http://www.cspeirce.com/menu/library/aboutcsp/ransdell/leading.htm

RANSDELL, J. On Peirce's conception of the iconic Sign. Ver. 2.0. Texas: Dept. of Philosophy, Texas Tech University, 1997. Disponible en Arisbe The Peirce Gateway: http://www.cspeirce.com/menu/library/aboutcsp/ransdell/iconic.htm

RICOEUR, P. La memoria, la historia, el olvido. Buenos Aires: Fondo de Cultura Económica, 2000.

SHAPIRO, Michel. Aspects of a Neo-Peircean Linguistics: Language History as Linguistic Theory. In SHAPIRO, M. (Ed.), The Peirce Seminar Papers. Essays in Semiotic Analysis, Volume V. NY/Oxford: Berghahn Books, 2002, p. 108-126.

Licenciado en Comunicación Social y Doctorando en Socio- semiótica del Centro de Estudios Avanzados de esa institución. Integrante del Programa de investigación Estudios sobre la Memoria del Centro de 
Estudios Avanzados de la Universidad Nacional de Córdoba, Argentina. Integrante de proyecto de investigación radicado en SECyT, tipo A, titulado Estudios sociolingüísticos interaccionales de base etnográfica. lenguaje, gestualidad y performance, dirigido por la

Dra. Isolda Carranza. Investigador y Autor de libro "Laboratorio de Hemoderivados Presidente Illía, de la Universidad Nacional de Córdoba" invitado por la casa de altos estudios.

Esta obra está licenciada sob uma Licença Creative Commons. 